\title{
Evaluation of Serodia Myco II particle agglutination test for detecting Mycoplasma pneumoniae antibody: comparison with $\mu$-capture ELISA and indirect immunofluorescence
}

\author{
C E Barker, M Sillis, T G Wreghitt
}

\begin{abstract}
The Serodia Myco II particle agglutination test, which the manufacturers claim exclusively detects IgM antibody, was compared with two IgM-specific tests, a $\mu$-capture ELISA, and indirect immunofluorescence for their ability to detect recent Mycoplasma pneumoniae infection. In general there was good agreement among the three tests, all three having similar sensitivity. One hundred and nine $(78 \%)$ of serum samples gave concordant results in all three assays. Several sera gave positive particle agglutination titres, however, while being negative by the two other assays, and the Serodia Myco II test may not be as specific for detecting $M$ pneumoniae IgM as the other two tests.

While the Serodia Myco II test may be a good screening assay, it is unlikely to be a definitive test for $M$ pneumoniae IgM, but may be better than the complement fixation test, particularly in younger patients in whom $M$ pneumoniae $\operatorname{IgM}$ is found more frequently.
\end{abstract}

Mycoplasma pneumoniae infection is frequently associated with severe pulmonary and nonpulmonary disease in man. ${ }^{1}$ Early diagnosis is important because the infection often responds well to appropriate antibiotics. The culture of Mycoplasma pneumoniae, although a sensitive indicator of infection, is difficult, and due to its fastidious nature is too slow to be of diagnostic value. Most laboratories still rely on complement fixation test for diagnosis of $M$ pneumoniae infection-a test shown to be both non-specific and insensitive. ${ }^{23}$ Tests for detection of $M$ pneumoniae $\operatorname{IgM},{ }^{4-7}$ while providing an accurate indication of recent infection when positive, are only available in a few laboratories.

It was felt that a commercial kit, marketed for detection of recent $M$ pneumoniae infection, warranted evaluation against well established $\mu$-capture ELISA and immunofluorescence tests to investigate its diagnostic potential in this context.

\section{Methods}

A total of 140 samples of serum from 96 patients with clinical features compatible with $M$ pneumoniae infection were selected.

The complement fixation test was performed as described by Bradstreet and Taylor ${ }^{8}$ using a microtitre system, overnight fixation, and antigen provided by the Public Health Laboratory Service Division of Microbiological Reagents and Quality Control, Central Public Health Laboratory, Colindale, London.

The $\mu$-capture ELISA was performed as previously described. ${ }^{5}$ Negative and positive control sera were selected as previously described $^{7}$ and allocated 0 arbitrary units and 100 $\mathrm{u}$, respectively. The positive control serum was diluted in negative control serum to give dilutions containing $33,10,3.3,1,0.33$ and $0.1 \mathrm{u}$. Sera with $\geqslant 0.33$ u of $M$ pneumoniae-specific IgM were regarded as positive.

The indirect immunofluorescence antibody (IFAT) test was performed as previously described. ${ }^{4} \operatorname{IgM}, \operatorname{IgA}$, and $\operatorname{IgG}$ were detected by means of anti-human Ig fluorescein isothiocyanate (FITC) conjugate (IgM and IgG, Wellcome Diagnostics, IgA, Miles). Sera with titres of $\geqslant 4(\operatorname{IgM}), \geqslant 16(\operatorname{IgA})$, or $\geqslant 64(\mathrm{IgG})$ were regarded as indicating recent $M$ pneumoniae infection.

The Serodia Myco II gelatin particle agglutination test (Fujirebio, Japan) is marketed in the United Kingdom by Mast Diagnostics, Bootle, and was performed according to the manufacturer's instructions. It is based on the principle that gelatin particles sensitised with $M$ pneumoniae cell membrane components are agglutinated in the presence of $M$ pneumoniae antibody. Serum samples were inactivated at $56^{\circ} \mathrm{C}$ for 30 minutes. Rigid U-well microtitre plates (supplied with the kits) were soaked in detergent solution overnight and then rinsed thoroughly under running tap water. They were then washed with distilled water and dried. Using the serum diluent supplied, $25 \mu \mathrm{l}$ serum samples were double diluted to give dilutions of 1 in 10 to 1 in 10240. Sensitised and unsensitised lyophilised gelatin particles were suspended in diluent. Twenty five microlitre drops of the unsensitised particle suspension were added to the 1 in 10 serum dilutions to give a final dilution of 1 in 20 , and $25 \mu \mathrm{l}$ drops of the sensitised particle suspension were added to the remaining wells giving final dilutions of 1 in 40 to 1 in 20480 . The plates were shaken for 30 seconds and then covered and left undisturbed on a level surface at room temperature for three hours (or overnight).

The test was initially calibrated using the control sera dilution series. Each batch of tests included control wells containing $25 \mu \mathrm{l}$ of 
diluent and $25 \mu \mathrm{l}$ of the particle suspensions and dilutions of a reactive control serum of known titre, supplied with the kit.

Buttons or compact, smooth rings of particles in the bottom of the wells were read as negative agglutination patterns and a more extensive ring as positive. Titres of $\geqslant 40$ were regarded as positive.

The control series used for the initial calibration of the particle agglutination test gave titres of $\geqslant 40$ only with serum containing $\geqslant 0.33$ $\mu$-capture units. These tests are therefore of similar sensitivity.

\section{Results}

When the 140 serum samples were tested with the Serodia Myco II particle agglutination,

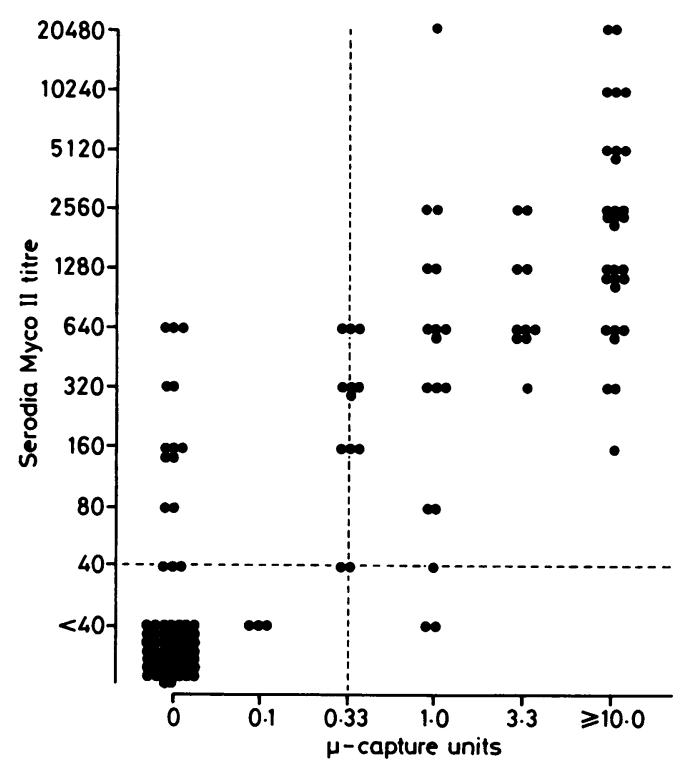

Figure 1 Correlation between results in the Serodia Myco II particle agglutination test and $\mu$-capture ELISA.

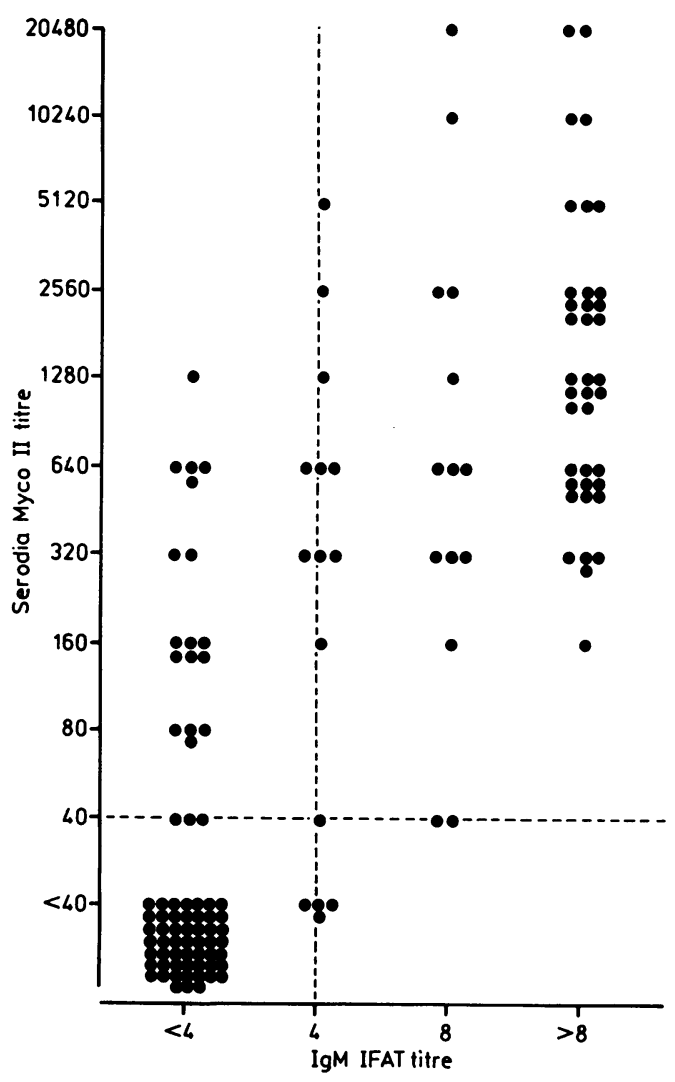

Figure 2 Correlation between results in Serodia Myco II particle agglutination test and IgM IFAT.

$\mu$-capture ELISA, and indirect immunofluorescence tests, similar results were obtained (figs 1 and 2). Of the 140 sera, only one produced a positive agglutination pattern with the unsensitised particle suspension. Although the manufacturer gives details of a method to absorb out factors causing nonspecific agglutination, there was insufficient serum for this to be performed. One hundred and nine of $139\left(78^{\circ}{ }_{0}\right)$ serum samples gave

Results of serological tests for M pneumoniae antibodies for those sera showing discrepancies between the Serodia Myco II particle agglutination test and both IgM tests

\begin{tabular}{|c|c|c|c|c|c|c|}
\hline \multirow[b]{2}{*}{ Serum number } & \multirow[b]{2}{*}{ Particle agglutination titre } & \multirow[b]{2}{*}{$\mu$-capture ELISA units } & \multicolumn{3}{|c|}{ IFAT titre } & \multirow[b]{2}{*}{$C F T$} \\
\hline & & & $\operatorname{Ig} M$ & $\operatorname{Ig} G$ & $\operatorname{Ig} A$ & \\
\hline 30 & 80 & 0 & $<4$ & 8 & $<4$ & 64 \\
\hline 31 & 160 & 0 & $<4$ & 16 & $<4$ & 128 \\
\hline 32 & 40 & 0 & $<4$ & 16 & $<4$ & 64 \\
\hline 35 & 640 & 0 & $<4$ & $>64$ & $<4$ & 128 \\
\hline 73 & 160 & 0 & $<4$ & 16 & 8 & 128 \\
\hline 74 & 160 & 0 & $<4$ & 16 & 8 & 128 \\
\hline 79 & 640 & 0 & $<4$ & 32 & 4 & 128 \\
\hline 106 & 160 & 0 & $<4$ & 32 & 8 & 64 \\
\hline 116 & 40 & 0 & $<4$ & 32 & 4 & 128 \\
\hline 124 & 320 & 0 & $<4$ & 64 & 4 & $>256$ \\
\hline 299 & 80 & 0 & $<4$ & $>64$ & 16 & $>256$ \\
\hline 420 & 160 & 0 & $<4$ & $>64$ & 4 & not tested \\
\hline 34 & 320 & 0 & 8 & $>64$ & 8 & 128 \\
\hline 135 & 40 & 0 & 8 & 16 & 8 & 64 \\
\hline 265 & 640 & 0 & 8 & 32 & 16 & 64 \\
\hline 17 & 40 & $0 \cdot 3$ & $<4$ & 32 & $<4$ & 128 \\
\hline 53 & 640 & $0 \cdot 3$ & $<4$ & $>64$ & 8 & $>256$ \\
\hline 58 & 160 & $0 \cdot 3$ & $<4$ & 64 & 8 & 64 \\
\hline 63 & 80 & $1 \cdot 0$ & $<4$ & 16 & $<4$ & 128 \\
\hline 64 & 80 & $1 \cdot 0$ & $<4$ & 16 & 8 & $>256$ \\
\hline 80 & 160 & $0 \cdot 3$ & $<4$ & 16 & $<4$ & 128 \\
\hline 96 & 640 & $>10$ & $<4$ & 64 & 64 & $>256$ \\
\hline 188 & 320 & 0.3 & $<4$ & 64 & 16 & $>256$ \\
\hline 410 & 1280 & $1 \cdot 0$ & $<4$ & $<8$ & 4 & $>256$ \\
\hline 24 & $<40$ & $1 \cdot 0$ & $<4$ & $<8$ & $<4$ & \\
\hline 407 & $<40$ & 1.0 & $<4$ & 64 & not tested & 256 \\
\hline 21 & $<40$ & 0 & 4 & 8 & $<4$ & not tested \\
\hline 22 & $<40$ & 0 & 4 & 16 & $<4$ & 128 \\
\hline 26 & $<40$ & 0 & 4 & 8 & $<4$ & 64 \\
\hline 395 & $<40$ & 0 & 4 & 8 & 16 & 256 \\
\hline
\end{tabular}


concordant results with all three tests. While generally there was good agreement among the results of $\mu$-capture, particle agglutination, and IgM IFAT, $30\left(22^{\circ}\right.$ ) sera gave discrepant results (table). Of these, 12 gave positive particle agglutination titres of between 40 and 640 in the absence of positive results from the other two tests. All had detectable IgG and eight were shown to have IgA by immunofluorescence, but only three had titres suggestive of recent $M$ pneumoniae infection. Another 12 sera were also positive in the particle agglutination test but in only one of the other two IgM tests (table). Another six sera were negative in the particle agglutination test and in one of the IgM tests, but were positive in the remaining IgM test (table).

\section{Discussion}

Most methods for the detection of $M$ pneumoniae IgM antibody, though sensitive and specific, are not widely available. In view of the response of $M$ pneumoniae infection to appropriate antibiotic treatment, there is a need for a more rapid and reliable technique than the complement fixation test. For use in this context, we investigated the Serodia Myco II particle agglutination test, which, the manufacturers claim, "exclusively detects IgM antibody" and compared it with $\mu$-capture ELISA and IgM indirect immunofluorescence tests, which have been found previously to have similar sensitivity and specificity. ${ }^{5}$

We found generally good agreement among the three tests, but $12\left(8 \cdot 6^{\circ}{ }_{0}\right)$ sera gave positive particle agglutination titres while being negative by the two reference assays. As all three tests were found to have similar sensitivity for detecting $M$ pneumoniae IgM by testing them with a standard dilution series, it is unlikely that the sera giving discrepant results did so because of a difference in sensitivity. The Serodia test may therefore not be as specific for detecting $M$ pneumoniae IgM as the other two tests. The $\mu$-capture ELISA and indirect immunofluorescence tests use specific antibodies directed against human IgM; the particle agglutination test does not.
A proportion $\left(66^{\circ}\right)$ of the sera which were positive in the particle agglutination test, but negative in the two other tests, contained $M$ pneumoniae specific IgA (table). It is conceivable that these patients may have experienced recent $M$ pneumoniae infection, but as there was no correlation between $M$ pneumoniae-specific IgA indirect immunofluorescence and particle agglutination antibody titres this seems unlikely. There was also no relation between particle agglutination positivity, IgM negativity and age of patient.

In conclusion, we feel that while the Serodia MycoII test is a useful screening assay (with very few false negative titres), for evidence of recent $M$ pneumoniae infection, we, unlike the manufacturers, would be unhappy to consider it as a definitive test for the presence of $M$ pneumoniae-specific IgM. It may be better than the complement fixation test, however, as an indicator of recent $M$ pneumoniae infection, particularly in younger patients in whom $M$ pneumoniae IgM is found more frequently. ${ }^{7}$

We thank Mast Diagnostics (Bootle) for providing the Serodia Myco II kits for use in this study.

1 Ali NJ, Sillis M, Andrews BE, Jenkins PF, Harrison BDW. The clinical spectrum and diagnosis of Mycoplasm pneumoniae infection. $Q J$ Med 1986;227:241-51.

2 Raisanen SM, Suni JI, Leinikki PO. Serological diagnosis of Mycoplasma pneumoniae infections by enzyme immunoassay. J Clin Pathol 1980;33:836-40.

3 Ponka A, Ponka T, Sarna S, Penttinen K. Questionable specificity of lipid antigen in Mycoplasma pneumoniae CF test in patients with extrapulmonary manifestation. $J$ Infect 1981;3:332-8.

4 Sillis $M$, Andrews B. A simple test for $M$ pneumoniae IgM. Zentralblatt für Backteriologie, Parasitenkunde, Infektionkrankheiten, und Hygiene Erste Abteilung Origininale. Reihe A Medizinische Mikrobiologie unt Parasitolgie 1978;241:239-40.

5 Wreghitt TG, Sillis $M$. A $\mu$-capture ELISA for detecting Mycoplasma pneumoniae IgM, comparison with indirect immunofluorescence and indirect ELISA. $J \mathrm{Hyg}(\mathrm{Camb}$ 1985;94:217-27.

6 Coombs RRA, Easter G, Matejtschuk P, Wreghitt TG. Redcell IgM-antibody capture assay for the detection of Mycoplasma pneumoniae-specific IgM. Epidemiol Infect Mycoplasma pne

7 Wreghitt TG, Sillis $M$. An investigation of the Mycoplasma pneumoniae infections in Cambridge in 1983 using $\mu$-capture ELISA, Indirect immunofluorescence and complement fixation tests. Isr J Med Sci 1987;23:704-8.

8 Bradstreet CMP, Taylor CED. Technique of complement fixation test applicable to the diagnosis of virus diseases. Month Bull Min Health (UK) and PHLS 1962;21: 